Article

Subscriber access provided by King Abdullah University of Science and Technology Library

\title{
The Role of Polymer Fractionation in Energetic Losses and Charge Carrier Lifetimes of Polymer: Fullerene Solar Cells
}

Derya Baran, Michelle S Vezie, Nicola Gasparini, Florent Deledalle, Jizhong Yao, Bob C. Schroeder, Hugo Bronstein, Tayebeh Ameri, Thomas Kirchartz, lain McCulloch, Jenny Nelson, and Christoph J Brabec

J. Phys. Chem. C, Just Accepted Manuscript • DOI: 10.1021/acs.jpcc.5b05709 • Publication Date (Web): 10 Aug 2015

Downloaded from http://pubs.acs.org on August 16, 2015

\section{Just Accepted}

"Just Accepted" manuscripts have been peer-reviewed and accepted for publication. They are posted online prior to technical editing, formatting for publication and author proofing. The American Chemical Society provides "Just Accepted" as a free service to the research community to expedite the dissemination of scientific material as soon as possible after acceptance. "Just Accepted" manuscripts appear in full in PDF format accompanied by an HTML abstract. "Just Accepted" manuscripts have been fully peer reviewed, but should not be considered the official version of record. They are accessible to all readers and citable by the Digital Object Identifier (DOI®). "Just Accepted" is an optional service offered to authors. Therefore, the "Just Accepted" Web site may not include all articles that will be published in the journal. After a manuscript is technically edited and formatted, it will be removed from the "Just Accepted" Web site and published as an ASAP article. Note that technical editing may introduce minor changes to the manuscript text and/or graphics which could affect content, and all legal disclaimers and ethical guidelines that apply to the journal pertain. ACS cannot be held responsible for errors or consequences arising from the use of information contained in these "Just Accepted" manuscripts. 


\title{
The Role of Polymer Fractionation in Energetic
}

\section{Losses and Charge Carrier Lifetimes of}

\section{Polymer: fullerene Solar Cells}

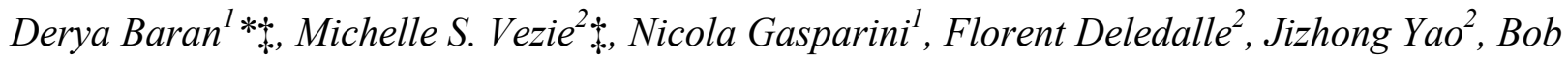 \\ C. Schroeder ${ }^{3}$, Hugo Bronstein ${ }^{3}$, Tayebeh Ameri ${ }^{1}$, Thomas Kirchartz ${ }^{4,5}$, Iain McCulloch ${ }^{3}$, Jenny \\ Nelson ${ }^{2}$, Christoph J. Brabec ${ }^{1,6}$ \\ ${ }^{1}$ Institute of Materials for Electronics and Energy Technology (i-MEET), Friedrich-Alexander \\ University of Erlangen-Nuremberg, Martensstraße 7, 91058, Erlangen, Germany \\ ${ }^{2}$ Center for Plastic Electronics, Department of Physics, Imperial College London, London SW7 \\ 2AZ, United Kingdom \\ ${ }^{3}$ Center for Plastic Electronics, Department of Chemistry, Imperial College London, London \\ SW7 2AZ, United Kingdom \\ ${ }^{4}$ IEK5-Photovoltaics, Forschungs zentrum Jülich, 52425 Jülich, Germany \\ ${ }^{5}$ Faculty of Engineering and CENIDE, University of Duisburg-Essen, Carl-Benz-Straße 199, \\ 47057 Duisburg, Germany \\ ${ }^{6}$ Bavarian Center for Applied Energy Research (ZAE Bayern), Haberstr. 2a, 91058 Erlangen, \\ Germany
}

\section{Corresponding Author}

*Dr. Derya Baran

Current Address: Center for Plastic Electronics, Department of Chemistry, Imperial College London, London SW7 2AZ, United Kingdom

Telephone number: +44 2075945866

Current e-mail: d.baran@imperial.ac.uk 
Keywords: charge transfer states, carrier lifetime, charge collection, organic solar cells, radiative open circuit voltage

\begin{abstract}
Non-radiative recombination reduces the open-circuit voltage relative to its theoretical limit and leads to reduced luminescence emission at a given excitation. Therefore it is possible to correlate changes in luminescence emission with changes in open-circuit voltage and in the charge carrier lifetime. Here we use luminescence studies combined with transient photovoltage and differential charging analyses to study the effect of polymer fractionation in indacenoedithiophene-co-benzothiadiazole (IDTBT):fullerene solar cells. In this system, polymer fractionation increases electroluminescence emission at the same injection current and reduces non-radiative recombination. High molecular weight and fractionated IDTBT polymers exhibit higher carrier lifetime-mobility product compared to their non-fractionated analogues, resulting in improved solar cell performance.
\end{abstract}

\title{
Introduction
}

In polymer:fullerene solar cells, the open-circuit voltage $\left(V_{\mathrm{oc}}\right)$ is usually limited by recombination at the interface between donor and acceptor. Thus, it varies with the energy difference between the highest occupied molecular orbital of the donor $\left(\mathrm{HOMO}_{\mathrm{D}}\right)$ and the lowest unoccupied molecular orbital of the acceptor $\left(\mathrm{LUMO}_{\mathrm{A}}\right){ }^{1-3}$ In practice the $\mathrm{HOMO}_{\mathrm{D}}-\mathrm{LUMO}_{\mathrm{A}}$ difference is insufficient to predict $V_{\text {oc }}$ due to differences in non-radiative recombination. ${ }^{4}$ The highest possible $V_{\text {oc }}$, denoted $V_{\text {oc,rad, }}$, can be achieved when only radiative recombination occurs and the absorbed photon flux is balanced exactly by the emitted flux under open-circuit 
conditions; this is called the radiative limit. ${ }^{5-10}$ In a practical solar cell both $V_{\text {oc }}$ and the LED quantum efficiency, $Q_{\mathrm{LED}}$, are reduced relative to their thermodynamic limits by non-radiative recombination pathways, the degree of which can be quantified via a reciprocity theorem. ${ }^{11-17}$ Therefore, it is of high interest in the field of organic photovoltaics to reduce these non-radiative recombination losses, thereby bringing the $V_{\mathrm{oc}}$ closer to the radiative limit. Recently, indacenodithiophene (IDT) copolymers have shown promising field-effect transistor mobilities and solar cell performance. ${ }^{18-22}$ Enhanced co-planarity of the polymer backbone has been hypothesized to lead to reduced energetic disorder. ${ }^{23,24}$ IDT-co-benzothiadiazole polymers have achieved up to $6.5 \%$ PCE with device optimization and material purification. ${ }^{25}$ The role of polymer molecular weight on solar cell performance has been well studied $^{25-29}$; however, the detailed analysis of the recombination processes in fractionated polymer devices remains comparatively unexplored. ${ }^{29,30}$

In this work, we describe how fractionation has an impact on energetic losses and charge transport in IDTBT: $\mathrm{PC}_{70} \mathrm{BM}$ bulk-heterojunction $(\mathrm{BHJ})$ solar cells. In particular, we use the reciprocity relation between non-radiative recombination and electroluminescence to explain the reduced energetic losses in $\mathrm{IDTBT}_{-} \mathrm{HM}_{\mathrm{w}}$ : $\mathrm{PC}_{70} \mathrm{BM}$ solar cells induced by fractionation and higher molecular weight by combining electroluminescence spectroscopy (EL) and Fouriertransform photocurrent spectroscopy (FTPS). The degree of non-radiative recombination, defined as the difference between $V_{\text {oc,rad }}$ and $V_{\text {oc }}$ and denoted $\Delta V_{\mathrm{oc}}$, is found to reduce upon fractionation and with increasing molecular weight. Furthermore, for the same system, we analyze the origin of enhanced photocurrent in terms of charge carrier lifetime and mobility using transient photovoltage (TPV), differential charging, charge extraction (CE) at short circuit and photo-induced charge carrier extraction by linearly increasing voltage technique (photo- 
CELIV) measurements. The combination of mobility and lifetime measurements shows that the mobility-lifetime product, which determines charge-carrier collection, is enhanced for the case of high molecular weight devices relative to devices made with low molecular weight and nonfractionated polymers.

\section{Results and Discussion}

We studied films and devices made from three IDTBT polymers; IDTBT-NF is not fractionated, and IDTBT-LM ${ }_{\mathrm{w}}$ and IDTBT-HM $\mathrm{w}$ are the low and high molecular weight fractions. The gel permeation chromatography traces and molecular weight information are presented in Figure S1 and Table S1, respectively.

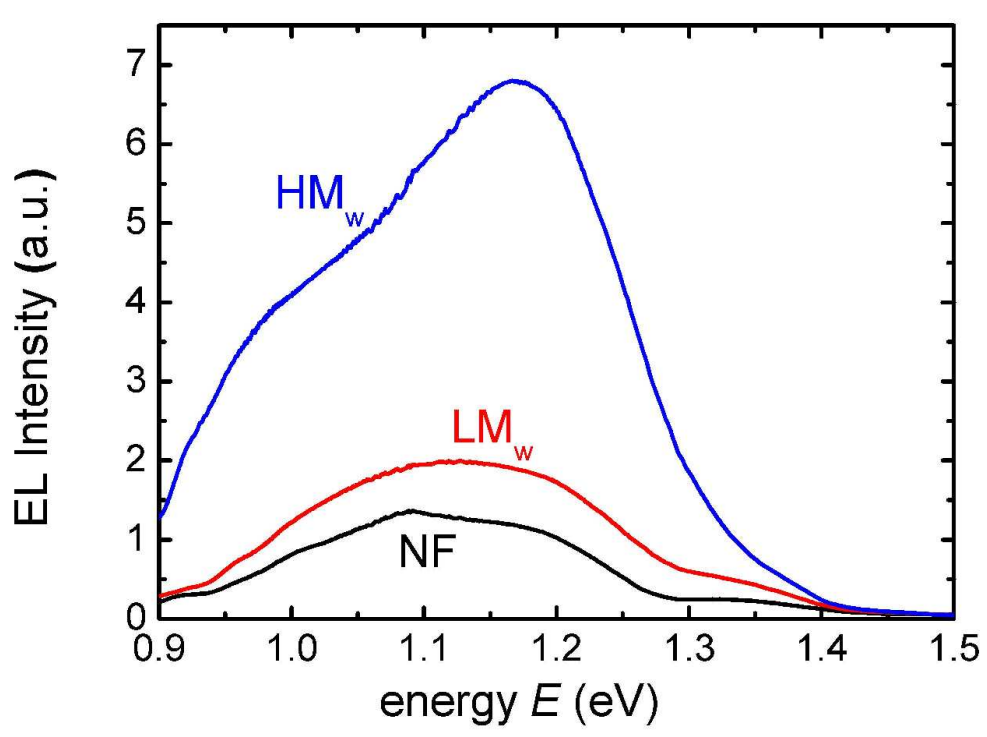

Figure 1 Electroluminescence spectra of IDTBT: $\mathrm{PC}_{70} \mathrm{BM}$ blend devices at the same current injection of $100 \mathrm{~mA} \mathrm{~cm}^{-2}$. 
Figure 1 shows the electroluminescence (EL) of IDTBT:PC ${ }_{70} \mathrm{BM}$ blend devices, with active layer thicknesses of $75 \pm 5 \mathrm{~nm}$, was measured under a constant current injection density of 100 $\mathrm{mAcm}^{-2}$; the spectral shape of some samples was checked for a range of injection currents down to $22 \mathrm{~mA} \mathrm{~cm}^{-2}$ and was found to be independent of current. ${ }^{31}$ The EL intensity increased from the IDTBT-NF: $\mathrm{PC}_{70} \mathrm{BM}$ blend to the IDTBT-HM $\mathrm{w}_{\mathrm{w}}$ : $\mathrm{PC}_{70} \mathrm{BM}$ blend at the same current injection indicating a relatively higher emissive quantum yield for the charge transfer (CT) state for IDTBT-HM $\mathrm{w}_{\mathrm{w}}: \mathrm{PC}_{70} \mathrm{BM}$ devices. It can be shown (see the Supporting Information for details) that the voltage loss $\Delta V_{\text {oc }}$ due to non-radiative recombination can be related to the LED quantum efficiency $Q_{\text {LED }}$ via

$$
\Delta V_{\mathrm{oc}}=V_{\mathrm{oc}, \mathrm{rad}}-V_{\mathrm{oc}}=-\frac{k T}{q} \ln \left[Q_{\mathrm{LED}}\right]
$$

Here, $V_{\text {oc,rad }} \approx k T / q \ln \left(J_{\mathrm{sc}} / J_{0, \text { rad }}\right)$ is the radiative limit to the open-circuit voltage, $J_{\text {sc }}$ is the device short circuit current density, $J_{0, \text { rad }}$ is the saturation current density for radiative recombination and $T$ is the temperature $(300 \mathrm{~K})$. The radiative saturation current density $\left(J_{0, \text { rad }}\right)$, is defined as the current due to blackbody radiation $\left(\phi_{\mathrm{bb}}\right)$, and can therefore be calculated according to:

$$
J_{0, \mathrm{rad}}=\mathrm{q} \cdot \int_{0}^{\infty} E Q E_{\mathrm{pV}}(E) \cdot \phi_{\mathrm{bb}}(E) d E
$$

where $E Q E_{\mathrm{PV}}$ is the photovoltaic external quantum efficiency. Similarly, $J_{\mathrm{sc}}$ is defined in terms of the solar flux density $\left(\phi_{\text {sun }}\right)$ : 


$$
J_{\mathrm{sc}}=\mathrm{q} \cdot \int_{0}^{\infty} E Q E_{\mathrm{PV}}^{\prime}\left(E^{\prime}\right) \cdot \phi_{\mathrm{sun}}\left(E^{\prime}\right) d E^{\prime}
$$

At the radiative limit, all the charges recombine radiatively, so the current at short-circuit must be balanced by the radiative current at open-circuit.

We investigated $E Q E_{\mathrm{PV}}$, the spectral photovoltaic external quantum efficiency, using FTPS measurements on the same devices in order to determine $V_{\text {oc,rad }}$ and hence $\Delta V_{\text {oc }}$ through the reciprocity relations outlined in the Supporting Information. Figure 2 depicts the experimental $E Q E_{\mathrm{PV}}$ (solid lines) for blend devices made from IDTBT-NF (Figure 2a), IDTBT-LM ${ }_{\mathrm{w}}($ Figure

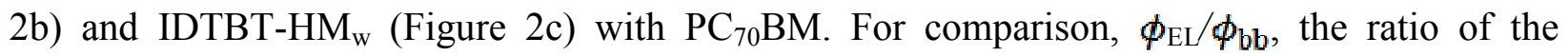
emitted photon flux $\phi_{\mathrm{EL}}$ obtained from electroluminescence for each device to the photon flux $\phi_{\mathrm{bb}}$ expected for a room-temperature black body at the same photon energy, which by reciprocity is another measure of $E Q E$, is also plotted (dashed lines). In all cases polymer absorption is visible at high energies followed by the distinct absorption shoulder of the $\mathrm{PC}_{70} \mathrm{BM}$ at around $1.8 \mathrm{eV}$. Below the fullerene absorption shoulder, there is a low energy absorption in the spectrum likely representing the $\mathrm{CT}$ state absorption at around 1.40-1.45 eV for IDTBT: $\mathrm{PC}_{70} \mathrm{BM}$ blends. $E Q E_{\mathrm{PV}}$ at lower photon energies is estimated from $\phi_{\mathrm{EL}} / \phi_{\mathrm{bb}}$, which follows experimental $E Q E_{\mathrm{PV}}$ faithfully at higher energies, as expected from reciprocity. 


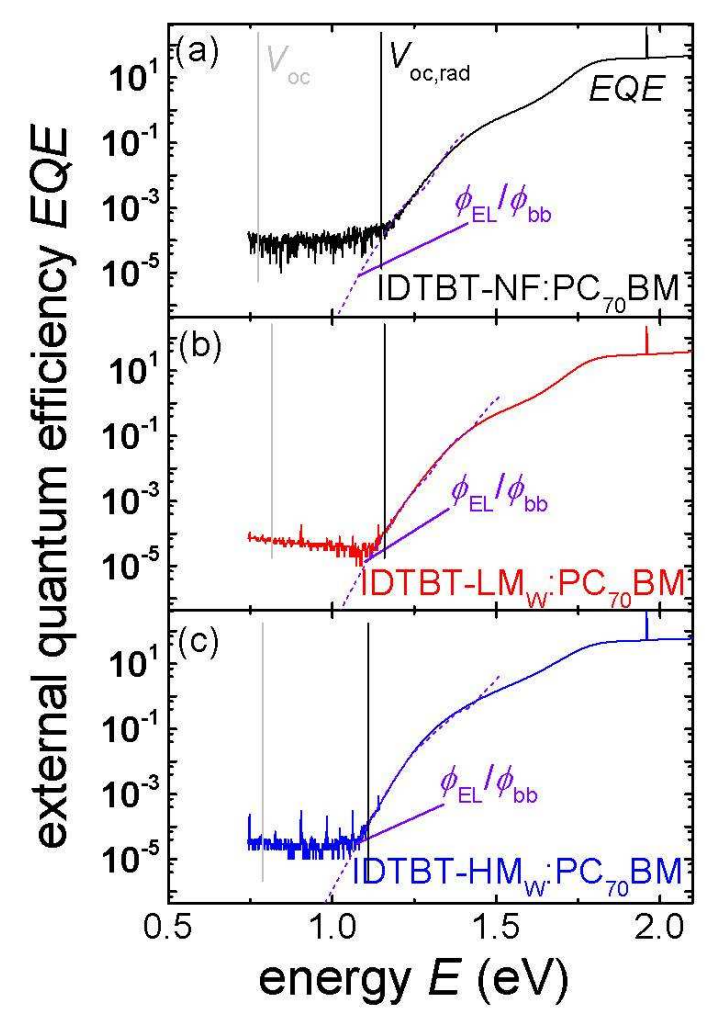

Figure 2 Semi-logarithmic plots of experimental photocurrent external quantum efficiency $\left(E Q E_{\mathrm{PV}}\right.$, solid lines) and calculated $E Q E_{\mathrm{PV}}$ from $\mathrm{EL}$ (dashed lines) as a function of energy for IDTBT-NF/LM $/ \mathrm{wM}_{\mathrm{w}}: \mathrm{PC}_{70} \mathrm{BM}$ blends (a,b and c respectively).

Table 1 summarizes the values measured and calculated from FTPS and EL measurements. Interestingly, the IDTBT-HM $\mathrm{w}_{\mathrm{w}}$ device showed the lowest $V_{\mathrm{oc}, \text { rad }}$ value of $1.11 \mathrm{~V}$, with values of 1.15 and $1.16 \mathrm{~V}$ determined for $-\mathrm{NF}$ and $-\mathrm{LM}_{\mathrm{w}}$ devices respectively. It should be noted that the radiative open-circuit voltage depends on the energetic dependence of $E Q E_{\mathrm{PV}}$ and so the value of $V_{\text {oc,rad }}$ on its own does not indicate merit, but rather the difference between this value and the experimental $V_{\mathrm{oc}}$ is pertinent. This $\Delta V_{\mathrm{oc}}$, defined by Eq. (1) using Eq. (2) and (3), is found to be 0.37, 0.35 and $0.32 \mathrm{~V}$, for IDTBT-NF, $-\mathrm{LM}_{\mathrm{w}}$ and $-\mathrm{HM}_{\mathrm{w}}$, respectively. As seen from Table 1 , the IDTBT-HM $\mathrm{w}_{\mathrm{w}}$ : $\mathrm{PC}_{70} \mathrm{BM}$ blend yields the lowest radiative open-circuit voltage and the smallest 
$\Delta V_{\mathrm{oc}}$ compared to $-\mathrm{LM}_{\mathrm{w}}$ and $-\mathrm{NF}$ blends. In addition, the non-fractionated IDTBT-NF: PC ${ }_{70} \mathrm{BM}$ system has the smallest measured $V_{\text {oc }}$ and highest $\Delta V_{\text {oc }}$ indicating enhanced non-radiative recombination in the system. Note that according to Eq. (1), the EL quantum efficiency, obtained by integrating the EL spectrum, can also directly yield $\Delta V_{\text {oc }}$ : the system with the highest $Q_{\mathrm{LED}}$ value should correspond to the lowest $\Delta V_{\text {oc }}$, since non-radiative recombination results in values of $Q_{\mathrm{LED}}$ less than 1. For polymer:fullerene solar cells the EL is dominated by CT emission with typical $Q_{\mathrm{LED}}<10^{-6}$, resulting in a loss in $V_{\mathrm{oc}}$ due to non-radiative recombination of over $0.36 \mathrm{~V}$ at room temperature. ${ }^{32}$ In this experiment only relative EL flux densities were measured, so the differences in $\Delta V_{\text {oc }}$ between sets of two systems were calculated by dividing the two $Q_{\text {LED }}$ values at the same current injection, i.e.

$$
\Delta V_{\mathrm{oc} 2}-\Delta V_{\mathrm{oc} 1}=-k T \ln \left[{ }^{Q_{\mathrm{LED} 2}} /{ }_{Q_{\mathrm{LED} 1}}\right]
$$

These values were found to agree well with the values calculated using FTPS and EL together (see Table S2).

The measurement of voltage losses indicates a decrease in non-radiative recombination upon increasing the molecular weight of the polymer, so we would expect this effect to be mirrored in the recombination lifetime. In disordered photovoltaic materials, charge recombination lifetime, like mobility, is charge carrier density dependent and therefore lifetimes must be probed as a function of charge density in order to compare different material systems. Therefore transient photovoltage (TPV) measurements in combination with differential charging were undertaken; the methods are described in detail elsewhere. ${ }^{33-37}$ 
Figure 3a displays the charge carrier lifetime from TPV as a function of the charge density obtained from differential charging, showing that carriers in the IDTBT-HM $\mathrm{w}_{\mathrm{w}}$ devices were much longer lived than carriers in the IDTBT-LM ${ }_{\mathrm{w}}$ and IDTBT-NF devices at the same charge density (corresponding plot of the bimolecular recombination coefficient is shown in Figure S3). It should be noted that the devices measured were all made in the same device run, so any potential differences in the contacts, for example, are minimized; they were however different from the ones used for the EL/FTPS experiment, but showed similar characteristics (Table S4). Therefore, the finding of reduced $\Delta V_{\mathrm{oc}}$ for IDTBT-HM $\mathrm{W}_{\mathrm{w}}$ can be assigned to reduced nongeminate recombination, as evidenced by the increase in charge-carrier lifetime. The external LED quantum efficiencies estimated from the values of $\Delta V_{\mathrm{oc}}\left(\mathrm{Q}_{\mathrm{LED}} \approx \exp \left(-q \Delta V_{\mathrm{o}} \mathrm{d} / k T\right)^{16}\right.$ are in the range of $10^{-6}$ to $10^{-7}$ (Table 1 ). Thus, changes in radiative recombination have no effect on the total recombination rate and therefore on the charge carrier lifetime.

Table 1 Parameters used in calculation of non-radiative voltage losses ${ }^{a}$

\begin{tabular}{|c|c|c|c|}
\hline Polymers with $\mathrm{PC}_{70} \mathrm{BM}$ & IDTBT-NF & IDTBT-LM $_{w}$ & IDTBT-HM $_{w}$ \\
\hline$E_{\mathrm{g}}(\mathrm{eV})^{\mathrm{a}}$ & 1.7 & 1.7 & 1.7 \\
\hline$J_{\mathrm{sc}}\left(\mathrm{mA} / \mathrm{cm}^{2}\right)$ measured $^{\mathrm{b}}$ & 6.9 & 7.2 & 10.2 \\
\hline$J_{0, \text { rad }}\left(\mathrm{A} / \mathrm{cm}^{2}\right)$ calc. $^{\mathrm{c}}$ & $3.24 \times 10^{-20}$ & $2.02 \times 10^{-20}$ & $1.63 \times 10^{-19}$ \\
\hline$V_{\text {oc,rad }}(\mathrm{V})$ calc. $^{\mathrm{c}}$ & 1.150 & 1.160 & 1.110 \\
\hline$V_{\mathrm{oc}}(\mathrm{V})$ measured $^{\mathrm{b}}$ & 0.775 & 0.815 & 0.788 \\
\hline$\Delta V_{\mathrm{oc}}(\mathrm{V})^{\mathrm{d}}$ & 0.37 & 0.35 & 0.32 \\
\hline $\mathrm{Q}_{\text {LED }}$ at $100 \mathrm{mAcm}^{-2}$ & $5.91 \times 10^{-7}$ & $1.28 \times 10^{-6}$ & $4.10 \times 10^{-6}$ \\
\hline
\end{tabular}


taken from the $J-V$ curve. ${ }^{\mathrm{c}} J_{0 \text {,rad }}$ and $V_{\text {oc,rad }}$ were calculated from EL and FTPS measurements and ${ }^{\mathrm{d}} \Delta V_{\mathrm{oc}}$ from $V_{\mathrm{oc}, \mathrm{rad}}-V_{\mathrm{oc}}$.

In order to evaluate the effect of charge carrier dynamics on solar cell performance, we compare the mobility-lifetime product $(\mu \tau)$, a measure of charge carrier collection efficiency, for different systems under similar conditions. ${ }^{38,39}$ Probing the mobility $\mu$ with charge extraction at short circuit, $^{40}$ we find only small differences in mobility for the different systems. Since the charge carrier lifetime $\tau$ was measured at open circuit and the carrier mobility was measured at short circuit, there is minimal overlap in charge densities between the two measurements. Mobility is not as strongly dependent on charge density as lifetime, so the mobility data were extrapolated over the charge density range of the TPV experiment, thus enabling a calculation of $\mu \tau$. Figure $3 \mathrm{~b}$ clearly shows that $\mathrm{HM}_{\mathrm{w}}$ devices exhibit significantly improved charge carrier collection relative to the NF and $\mathrm{LM}_{\mathrm{w}}$ devices, in spite of slightly lower mobility. As a further probe of charge carrier dynamics we measured lifetime and mobility for a similar set of devices using photoCELIV. ${ }^{41,42}$ Also by this method a significantly higher $\mu \tau$ was observed for the highest molecular weight polymer (Table S5). 

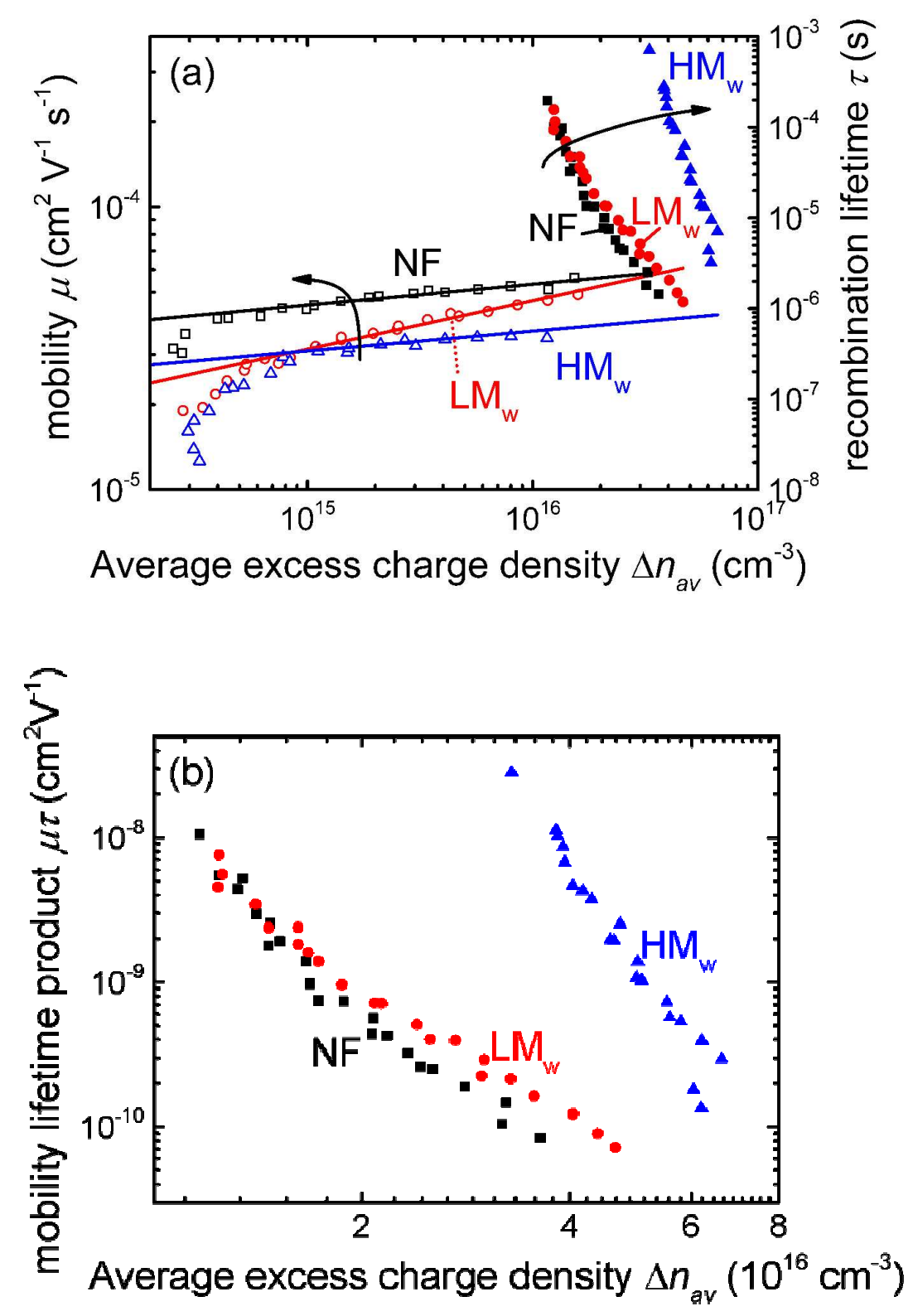

Figure 3 (a) Average carrier mobility, measured by charge extraction at short circuit (open symbols), and recombination lifetime, measured by transient photovoltage (solid symbols). The solid lines are the fits and resulting extrapolation of the mobility data over the charge density range of the transient photovoltage experiment. (b) Mobility-lifetime product, calculated over the charge density range of the lifetime data by extrapolating the mobility data. 
The combined measurements of the degree of non-radiative recombination, charge carrier recombination lifetime and mobility for the three sets of devices provide a detailed explanation of the differences we observe in the current-voltage characteristics of solar cells made from these blends (Figure 4). Notably, the $J_{\mathrm{sc}}$ of the IDTBT-HM $\mathrm{W}_{\mathrm{w}}$ : $\mathrm{PC}_{70} \mathrm{BM}$ devices is significantly greater than that of the $-\mathrm{NF}$ and $-\mathrm{LM}_{\mathrm{w}}$ devices. This photocurrent enhancement cannot be explained by the polymer optical properties: the absorption and photoluminescence (PL) spectra of the polymers are essentially identical (see Figure S2), as are the device film thicknesses $( \pm 5 \mathrm{~nm})$. Furthermore, addition of $\mathrm{PC}_{70} \mathrm{BM}$ results in strong PL quenching in the visible region for all polymers, accompanied by intensified emission around $900 \mathrm{~nm}$ due to CT state emission. That said, the $\mathrm{HM}_{\mathrm{w}}$ blend quenches approximately $50 \%$ more than the $\mathrm{LM}_{\mathrm{w}}$ and NF blends, which is attributed to more efficient photo-induced charge separation between electron-donating and electron-accepting molecules. ${ }^{42-45}$ Moreover, Mott-Schottky analysis of blend devices indicates no difference in the apparent doping concentration before and after fractionation (Figure S6). Therefore it appears that the short-circuit current increase in the $\mathrm{HM}_{\mathrm{w}}$ blend is due to a higher efficiency of charge generation and/or charge collection, rather than any kind of optical effect. In addition, there are small differences in the $V_{\text {oc }}$ between the devices, which is unexpected since the polymer itself does not change, and the device architectures are identical; however, these differences are explained through differences in the radiative and non-radiative recombination. 


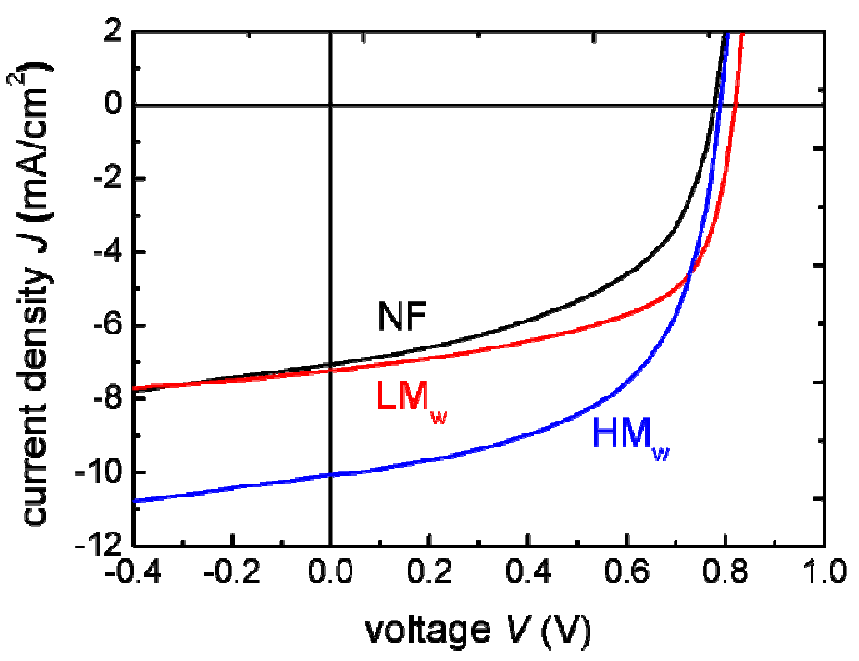

Figure 4 Current-voltage characteristics of the IDTBT-NF, $-\mathrm{LM}_{\mathrm{w}}$ and $\mathrm{HM}_{\mathrm{w}}$ devices used in this study to measure non-radiative voltage losses (black, red and blue lines respectively). All devices have an ITO / PEDOT:PSS / IDTBT:PC $70 \mathrm{BM} / \mathrm{Ca} / \mathrm{Ag}$ architecture.

\section{Conclusion}

In summary, we have successfully demonstrated that non-radiative losses can be reduced with fractionation and higher molecular weight in indacenodithiophene copolymers. Analysis of charge dynamics in the bulk-heterojunction devices revealed that increasing the molecular weight of IDTBT polymers increases the carrier lifetime, as anticipated due to the reduced nonradiative voltage losses. The increased lifetime results in an increased mobility-lifetime product,

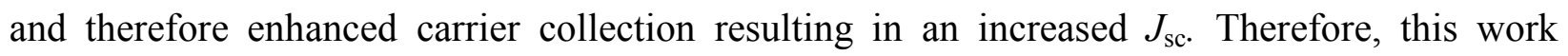
demonstrates a methodical evaluation of the losses due to non-geminate recombination, and 
provides a systematic explanation for the enhanced device performance with molecular weight observed in this system.

\section{Experimental Details}

Polymer materials. The polymer materials were synthesized according to Ref [25]. A portion of un-fractionated material, IDTBT-NF, was set aside and the rest was fractionated yielding high and low molecular weight fractions. The gel permeation chromatography traces for the materials are shown in Figure S1 and the corresponding molecular weight information is shown in Table S1.

Fabrication of Photovoltaic devices. All the devices were fabricated using the doctor-blade technique under ambient conditions. The devices for EL/FTPS and photo-CELIV were made at FAU Erlangen while the devices for TPV/CE were made at Imperial College. Pre-structured indium tin oxide (ITO) substrates were ultrasonic cleaned with acetone and isopropyl alcohol for 10 minutes each. After drying the substrates were coated with PEDOT:PSS (around $30 \mathrm{~nm}$ ) and then $70-90 \mathrm{~nm}$ thick active layers based on IDTBT:PC ${ }_{70} \mathrm{BM}(1: 3.5 \mathrm{wt}$ fraction in 1,2dichlorobenzene) were bladed. The total solution concentration used in Erlangen was $28 \mathrm{mg} \mathrm{ml}^{-1}$ while the concentration used at Imperial was $18 \mathrm{mg} \mathrm{ml}^{-1}$; blade coating speeds were adjusted to compensate and achieve similar device thicknesses. To complete the fabrication of the devices $15 \mathrm{~nm}$ of $\mathrm{Ca}$ and $100 \mathrm{~nm}$ of $\mathrm{Ag}$ were thermally evaporated through a mask (device areas were $10.4 \mathrm{~mm}^{2}$ (Erlangen) and $4.5 \mathrm{~mm}^{2}$ (Imperial)) under vacuum (about $1-5 \times 10^{-6} \mathrm{mbar}$ ). The $J-V$ characteristics were measured using a source measurement unit from BoTest. Illumination was provided by a solar simulator (Oriel Sol 1A, from Newport) with AM1.5G spectrum at $100 \mathrm{~mW}$ $\mathrm{cm}^{-2}$. 
$\boldsymbol{E} \boldsymbol{L}$. EL measurements were performed by using a chopper and applying a constant current $\left(100 \mathrm{~mA} \mathrm{~cm}^{-2}\right)$ supplied by an external current/voltage source through the devices which have an active area of $0.104 \mathrm{~cm}^{2}$. The emitted light was then collected by a monochromator and detected by liquid-nitrogen-cooled Ge detector. The spectrum was recorded by a standard lock-in technique. The system was wavelength calibrated.

FTPS. FTPS-EQE measurements were carried out using a Vertex 70 from Brucker optics, equipped with QTH lamp, quartz beam splitter and external detector option. A low noise current amplifier (DLPCA-200) is used to amplify the photocurrent produced upon illumination of the photovoltaic devices with light modulated by the FTIR. The output voltage of the current amplifier is fed back to the external detector port of the FTIR, in order to be able to use the FTIR's software to collect the photocurrent spectrum.

Transient photovoltage. The experimental details are as previously published. ${ }^{33-34}$

\title{
Current Addresses
}

B. Schroeder

Current address: Stanford University Shriram Center Department of Chemical Engineering 443 Via Ortega, Stanford, CA 94305-4125, USA

\author{
H. Bronstein \\ Department of Chemistry, University College London, Gordon Street, London WC1H 0AJ, \\ United Kingdom
}


I. McCulloch

Physical Sciences and Engineering Division, King Abdullah University of Science and

Technology (KAUST), Thuwal, Saudi Arabia, 23955-6900

\section{Author Contributions \\ \$These authors contributed equally.}

\section{Acknowledgment}

D.B. acknowledges the Bavarian Research Foundation (BFS) and Synthetic carbon allotropes project SFB 953 for financial support. M.S.V. is grateful to the EPSRC for a doctoral training award. J.Y. is grateful to Imperial College for a Rector's scholarship. J.N. acknowledges the EPSRC for grants EP/K030671/1, EP/K029843/ and the Supersolar Hub EP/J017361/1, and the Royal Society for a Wolfson Merit Award. TK acknowledges the DFG for support via the project 'Radiative Recombination in Organic Solar Cells'.

Supporting Information Available. Containing additional experimental details and supporting figures. This information is available free of charge via the Internet at http://pubs.acs.org

\section{References}

(1) Nelson, J.; Kirkpatrick, J.; Ravirajan, P. Factors Limiting the Efficiency of Molecular Photovoltaic Devices. Phys. Rev. B 2004, 69, 035337-11.

(2) Mutolo, K. L.; Mayo, E. I.; Rand, B. P.; Forrest, S. R.; Thompson, M. E. Enhanced Open-Circuit Voltage in Subphthalocyanine/C60 Organic Photovoltaic Cells. J. Am. Chem. Soc. 2006, 128, 8108-8109. 
(3) Sarangerel, K.; Ganzorig, C.; Fujihira, M.; Sakomura, M.; Ueda, K. Influence of the Work Function of Chemically Modified Indium\&ndash;Tin\&ndash;Oxide Electrodes on the Open-circuit Voltage of Heterojunction Photovoltaic Cells. Chem. Lett. 2008, 37, 778-779.

(4) Vandewal, K.; Widmer, J.; Heumueller, T.; Brabec, C. J.; McGeHee, M.; Leo, K.; Riede, M.; Salleo, A. Increased Open-Circuit Voltage of Organic Solar Cells by Reduced DonorAcceptor Interface Area. Adv. Mater. 2014, 26, 3839-3843.

(5) Ross, R. T. Some Thermodynamics of Photochemical Systems. J. Chem. Phys. 1967, 46, 4590-4593.

(6) Shockley, W.; Queisser, H. J. Detailed Balance Limit of Efficiency of P-N Junction Solar Cells. J. Appl. Phys. 1961, 32, 510-519.

(7) Kirchartz, T.; Rau, U.; Kurth, M.; Mattheis, J.; Werner, J. H. Comparative Study of Electroluminescence from $\mathrm{Cu}(\mathrm{In}, \mathrm{Ga}) \mathrm{Se} 2$ and Si Solar Cells. Thin Solid Films 2007, 515, 6238-6242.

(8) Tvingstedt, K.; Malinkiewicz, O.; Baumann, A.; Deibel, C.; Snaith, H. J.; Dyakonov, V.; Bolink, H. J. Radiative efficiency of lead iodide based perovskite solar cells. Sci. Rep. 2014, 4, 6071-7.

(9) Tress, W.; Marinova, N.; Inganäs, O.; Nazeeruddin, M. K.; Zakeeruddin, S. M.; Graetzel, M. Predicting the Open-Circuit Voltage of CH3NH3PbI3 Perovskite Solar Cells Using Electroluminescence and Photovoltaic Quantum Efficiency Spectra: the Role of Radiative and Non-Radiative Recombination. Adv. Energy Mater. 2015, 5, 1400812-1400816.

(10) Yamamoto, S.; Orimo, A.; Ohkita, H.; Benten, H.; Ito, S. Molecular Understanding of the Open-Circuit Voltage of Polymer:Fullerene Solar Cells. Adv. Energy Mater. 2012, 2, 229-237.

(11) Smestad, G.; Ries, H. Luminescence and Current-Voltage Characteristics of Solar Cells and Optoelectronic Devices. Sol. Energ. Mat. Sol. C. 1992, 25, 51-71.

(12) Vandewal, K.; Tvingstedt, K.; Gadisa, A.; Inganas, O.; Manca, J. V. On the Origin of the Open-Circuit Voltage of Polymer-Fullerene Solar Cells. Nat. Mater. 2009, 8, 904909.

(13) Rau, U.; Paetzold, U. W.; Kirchartz, T. Thermodynamics of Light Management in Photovoltaic Devices. Phys. Rev. B 2014, 90, 035211-16.

(14) Kirchartz, T.; Rau, U. Electroluminescence Analysis of High Efficiency $\mathrm{Cu}(\mathrm{In}, \mathrm{Ga}) \mathrm{Se} 2$ Solar Cells. J. Appl. Phys. 2007, 102, 104510-8.

(15) Kirchartz, T.; Helbig, A.; Reetz, W.; Reuter, M.; Werner, J. H.; Rau, U. Reciprocity between Electroluminescence and Quantum Efficiency Used for the Characterization of Silicon Solar Cells. Prog. Photovoltaics 2009, 17, 394-402.

(16) Rau, U. Reciprocity Relation between Photovoltaic Quantum Efficiency and Electroluminescent Emission of Solar Cells. Phys. Rev. B 2007, 76, 085303-8.

(17) Gruber, M.; Wagner, J.; Klein, K.; Hörmann, U.; Opitz, A.; Stutzmann, M.; Brütting, W. Thermodynamic Efficiency Limit of Molecular Donor-Acceptor Solar Cells and its Application to Diindenoperylene/C60-Based Planar Heterojunction Devices. Adv. Energy Mater. 2012, 2, 1100-1108.

(18) Holliday, S.; Donaghey, J. E.; McCulloch, I. Advances in Charge Carrier Mobilities of Semiconducting Polymers Used in Organic Transistors. Chem. Mater. 2013, 26, 647-663. 
(19) Xu, Y.-X.; Chueh, C.-C.; Yip, H.-L.; Chang, C.-Y.; Liang, P.-W.; Intemann, J. J.; Chen, W.-C.; Jen, A. K. Y. Indacenodithieno[3,2-b]Thiophene-Based Broad Bandgap Polymers for High Efficiency Polymer Solar Cells. Polym. Chem. 2013, 4, 5220-5223.

(20) Bronstein, H.; Leem, D. S.; Hamilton, R.; Woebkenberg, P.; King, S.; Zhang, W.; Ashraf, R. S.; Heeney, M.; Anthopoulos, T. D.; Mello, J. d.; et al. Indacenodithiophene-cobenzothiadiazole Copolymers for High Performance Solar Cells or Transistors via Alkyl Chain Optimization. Macromolecules 2011, 44, 6649-6652.

(21) Zhang, X.; Bronstein, H.; Kronemeijer, A. J.; Smith, J.; Kim, Y.; Kline, R. J.; Richter, L. J.; Anthopoulos, T. D.; Sirringhaus, H.; Song, K.; et al. Molecular Origin of High Field-Effect Mobility in an Indacenodithiophene-Benzothiadiazole Copolymer. Nat. Commun. 2013, 4, 2238-46.

(22) Venkateshvaran, D.; Nikolka, M.; Sadhanala, A.; Lemaur, V.; Zelazny, M.; Kepa, M.; Hurhangee, M.; Kronemeijer, A. J.; Pecunia, V.; Nasrallah, I. et al. Approaching DisorderFree Transport in High-Mobility Conjugated Polymers. Nature 2014, 515, 384-388.

(23) McCulloch, I.; Ashraf, R. S.; Biniek, L.; Bronstein, H.; Combe, C.; Donaghey, J. E.; James, D. I.; Nielsen, C. B.; Schroeder, B. C.; Zhang, W. Design of Semiconducting Indacenodithiophene Polymers for High Performance Transistors and Solar Cells. Acc. Chem. Res. 2012, 45, 714-722.

(24) Zhang, Y.; Zou, J.; Yip, H.-L.; Chen, K.-S.; Zeigler, D. F.; Sun, Y.; Jen, A. K. Y. Indacenodithiophene and Quinoxaline-Based Conjugated Polymers for Highly Efficient Polymer Solar Cells. Chem. Mater. 2011, 23, 2289-2291.

(25) Ashraf, R. S.; Schroeder, B. C.; Bronstein, H. A.; Huang, Z.; Thomas, S.; Kline, R. J.; Brabec, C. J.; Rannou, P.; Anthopoulos, T. D.; Durrant, J. R.; et al. The influence of Polymer Purification on Photovoltaic Device Performance of a Series of Indacenodithiophene Donor Polymers. Adv. Mater. 2013, 25, 2029-2034.

(26) Müller, C.; Wang, E.; Andersson, L. M.; Tvingstedt, K.; Zhou, Y.; Andersson, M. R.; Inganäs, O. Influence of Molecular Weight on the Performance of Organic Solar Cells Based on a Fluorene Derivative. Adv. Funct. Mater. 2010, 20, 2124-2131.

(27) Ma, W.; Kim, J. Y.; Lee, K.; Heeger, A. J. Effect of the Molecular Weight of Poly(3-hexylthiophene) on the Morphology and Performance of Polymer Bulk Heterojunction Solar Cells. Macromol. Rapid Commun. 2007, 28, 1776-1780.

(28) Ballantyne, A. M.; Chen, L.; Dane, J.; Hammant, T.; Braun, F. M.; Heeney, M.; Duffy, W.; McCulloch, I.; Bradley, D. D. C.; Nelson, J. The Effect of Poly(3-hexylthiophene) Molecular Weight on Charge Transport and the Performance of Polymer:Fullerene Solar Cells. Adv. Funct. Mater. 2008, 18, 2373-2380.

(29) Huang, Z.; Fregoso, E. C.; Dimitrov, S.; Tuladhar, P. S.; Soon, Y. W.; Bronstein, H.; Meager, I.; Zhang, W.; McCulloch, I.; Durrant, J. R. Optimisation of Diketopyrrolopyrrole:Fullerene Solar Cell Performance Through Control of Polymer Molecular Weight and Thermal Annealing. J. Mater. Chem. A 2014, 2, 19282-19289.

(30) Dimitrov, S. D.; Huang, Z.; Deledalle, F.; Nielsen, C. B.; Schroeder, B. C.; Ashraf, R. S.; Shoaee, S.; McCulloch, I.; Durrant, J. R. Towards Optimisation of Photocurrent From Fullerene Excitons in Organic Solar Cells. Energ. Environ. Sci. 2014, 7, 1037-1043.

(31) Gong, W.; Faist, M. A.; Ekins-Daukes,N. J.; Xu,Z.; Bradley,D. D. C.; Nelson, J. Kirchartz, T. Influence of Energetic Disorder on Electroluminescence Emission in Polymer:Fullerene Solar Cells. Phys. Rev. B. 2012, 86, 024201-9. 
(32) Vandewal, K.; Ma, Z.; Bergqvist, J.; Tang, Z.; Wang, E.; Henriksson, P.; Tvingstedt, K.; Andersson, M. R.; Zhang, F.; Inganäs, O. Quantification of Quantum Efficiency and Energy Losses in Low Bandgap Polymer:Fullerene Solar Cells with High Open-Circuit Voltage. Adv. Funct. Mater. 2012, 22, 3480-3490.

(33) Shuttle, C. G.; O’Regan, B.; Ballantyne, A. M.; Nelson, J.; Bradley, D. D. C.; de Mello, J.; Durrant, J. R. Experimental Determination of the Rate Law for Charge Carrier Decay in a Polythiophene: Fullerene Solar Cell. Appl. Phys. Lett. 2008, 92, 093311-3.

(34) Maurano, A.; Shuttle, C. G.; Hamilton, R.; Ballantyne, A. M.; Nelson, J.; Zhang, W.; Heeney, M.; Durrant, J. R. Transient Optoelectronic Analysis of Charge Carrier Losses in a Selenophene/Fullerene Blend Solar Cell. J. Phys. Chem. C 2011, 115, 5947-5957.

(35) Shuttle, C.; O’Regan, B.; Ballantyne, A.; Nelson, J.; Bradley, D.; Durrant, J. Bimolecular Recombination Losses in Polythiophene: Fullerene Solar Cells. Phys.Rev. B 2008, 78, 113201-4.

(36) Credgington, D.; Hamilton, R.; Atienzar, P.; Nelson, J.; Durrant, J. R. NonGeminate Recombination as the Primary Determinant of Open-Circuit Voltage in Polythiophene:Fullerene Blend Solar Cells: an Analysis of the Influence of Device Processing Conditions. Adv. Funct. Mater. 2011, 21, 2744-2753.

(37) Credgington, D.; Durrant, J. R. Insights from Transient Optoelectronic Analyses on the Open-Circuit Voltage of Organic Solar Cells. J. Phys. Chem. Lett. 2012, 3, 1465-1478.

(38) Schilinsky, P.; Waldauf, C.; Brabec, C. J. Recombination and loss Analysis in Polythiophene Based Bulk Heterojunction Photodetectors. Appl. Phys. Lett. 2002, 81, 38853887.

(39) Hawks, S. A.; Deledalle, F.; Yao, J.; Rebois, D. G.; Li, G.; Nelson, J.; Yang, Y.; Kirchartz, T.; Durrant, J. R. Relating Recombination, Density of States, and Device Performance in an Efficient Polymer: Fullerene Organic Solar Cell Blend. Adv. Energy Mater. 2013, 3, 12011209.

(40) Shuttle, C. G.; Hamilton, R.; Nelson, J.; O'Regan, B. C.; Durrant, J. R. Measurement of Charge-Density Dependence of Carrier Mobility in an Organic Semiconductor Blend. Adv. Funct. Mater. 2010, 20, 698-702.

(41) Mozer, A. J.; Sariciftci, N. S.; Lutsen, L.; Vanderzande, D.; Österbacka, R.; Westerling, M.; Juška, G. Charge transport and Recombination in Bulk Heterojunction Solar Cells Studied by the Photoinduced Charge Extraction in Linearly Increasing Voltage Technique. Appl. Phys. Lett. 2005, 86, 112104-3.

(42) Gasparini, N.; Katsouras, A.; Prodromidis, M. I.; Avgeropoulos, A.; Baran,D.; Salvador, M.; Fladischer, S.; Spiecker, E.; Chochos, C. L.; Ameri, T.; Brabec, C. J. Photophysics of Molecular-Weight-Induced Losses in Indacenodithienothiophene-Based Solar Cells. Adv. Funct. Mater. 2015, DOI: 10.1002/adfm.201501062.

(43) Snaith, H. J.; Arias, A. C.; Morteani, A. C.; Silva, C.; Friend, R. H. Charge Generation Kinetics and Transport Mechanisms in Blended Polyfluorene Photovoltaic Devices. Nano Lett. 2002, 2, 1353-1357.

(44) Kim, Y.; Cook, S.; Choulis, S. A.; Nelson, J.; Durrant, J. R.; Bradley, D. D. C. Organic Photovoltaic Devices Based on Blends of Regioregular Poly(3-hexylthiophene) and Poly(9,9-dioctylfluorene-co-benzothiadiazole). Chem. Mater. 2004, 16, 4812-4818.

(45) Baran, D.; Li, N.; Breton, A.-C.; Osvet, A.; Ameri, T.; Leclerc, M.; Brabec, C. J. Qualitative Analysis of Bulk-Heterojunction Solar Cells without Device Fabrication: An Elegant and Contactless Method. J. Am. Chem. Soc. 2014, 136, 10949-10955. 


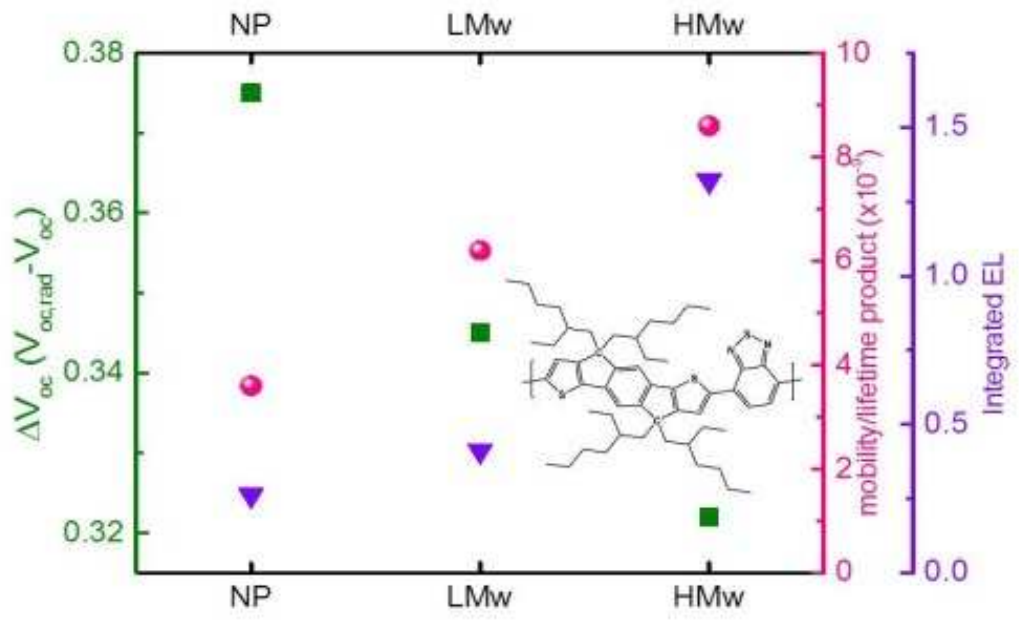

20

21 